\title{
A referenciação como construção sociocognitiva: o caso dos rótulos
}

\author{
Referentiality as sociocognitive building: the case of \\ labels
}

\author{
Ingedore G. Villaça Koch \\ UNICAMP/CNPQ
}

\begin{abstract}
In this article labeling will be explored as analytic focus for reference building under a sociocognitive perspective. It is pressuposed that textual processing depends not only on textual characteristics but also on language usera' sociocognitive characteristics. Thus the text is seen as the actual locus for interaction and interlocutors as active subjects who dialogically build themselves through it an are built by it.
\end{abstract}

\section{Keywords}

Labeling; Sociocognition; Reference; Text.

\section{Resumo}

Neste artigo explorar-se-á a rotulação como foco analítico da referenciação como construção sociocognitiva. Pressupõe-se que o processamento de um texto depende não só de características textuais, como também de características sociocognitivas dos usuários da língua. Assim, considera-se o texto o próprio lugar da interação e os interlocutores como sujeitos ativos que dialogicamente nele se constroem e por ele são construídos.

\section{Palavras-chave}

Rotulação; Sociocognição; Referencialidade; Text. 
$\grave{A}$

luz de uma perspectiva sociocognitiva e interacional, os processos cognitivos não são tomados como comportamentos previsíveis ou aprioristicamente concebidos, à margem das rotinas significativas da vida em sociedade, visto que o tipo de relação que se estabelece entre linguagem e cognição é de mútua constitutividade.

O processamento de um texto, portanto, depende não só de características textuais, como também de características sociocognitivas dos usuários da língua. Ele pressupõe um conjunto de atividades do ouvinte/leitor, de modo que se caracteriza como um processo ativo e contínuo de construção de sentidos, que se realiza na interação entre os interlocutores.

Dentro dessa concepção, considera-se o texto o próprio lugar da interação e os interlocutores como sujeitos ativos que - dialogicamente-nele se constroem e por ele são construídos. A produção de linguagem constitui atividade cognitivo-interativa altamente complexa de produção de sentidos, que se realiza, evidentemente, com base nos elementos lingüísticos presentes na superfície textual e na sua forma de organização, mas que requer não apenas a mobilização de um vasto conjunto de saberes, como também, sobretudo, a sua reconstrução no momento da interação verbal.

É dentro desse quadro que se procede a um deslocamento da noção de referência para a de referenciação. A língua não existe fora dos sujeitos sociais que a falam e fora dos eventos discursivos nos quais eles intervêm e nos quais mobilizam suas percepções, seus saberes, quer de ordem lingüística, quer de ordem sociocognitiva, ou seja, seus modelos de mundo. Estes, todavia, não são estáticos, (re)constroem-se tanto sincrônica como diacronicamente, dentro das diversas cenas enunciativas, de modo que, no momento em que se passa da língua ao discurso, torna-se necessário mobilizar conhecimentos - socialmente compartilhados e discursivamente (re)construídos -, bem como situar-se dentro das contingências históricas, para que se possa proceder aos encadeamentos 
discursivos. Passa-se, assim, a postular que a referenciação, bem como a progressão referencial, consistem na construção e reconstrução de objetos-de-discurso.

Desta forma, a referenciação é vista como atividade cognitivo-discursiva. O sujeito, por ocasião da interação verbal, mobiliza um conjunto de estratégias de ordem sociocognitiva e opera sobre o material lingüístico, procedendo a escolhas significativas para representar estados de coisas, com vistas à concretização de sua proposta de sentido (KOCH, 1999, 2002). Pela repetição constante de tais estratégias, estabiliza-se, por um lado, o modelo textual; por outro lado, porém, este modelo é continuamente reelaborado e modificado por meio de novas referenciações (SCHWARZ, 2000). Desta maneira, "endereços" ou nódulos cognitivos já existentes podem ser, a qualquer momento, modificados ou expandidos, de modo que, durante o processo de compreensão, desdobra-se uma unidade de representação extremamente complexa, pelo acréscimo sucessivo e intermitente de novas categorizações e/ou avaliações acerca do referente. Como exemplificação do que foi dito, passo a examinar o tipo de referenciação a que se vem denominando rotulação.

\section{A rotulação}

Sabemos que as formas ou expressões nominais são recurso dos mais eficientes para a construção e reconstrução de objetos-de-discurso. É fato bastante comum, em se tratando de remissão textual, o uso de uma forma nominal para categorizar ou recategorizar segmentos precedentes ou subseqüentes do co-texto, sumarizando-os e encapsulando-os (CONTE, 1996). Tem-se um rótulo sempre que o encapsulamento é feito por meio de uma expressão nominal (FRANCIS, 1994). Trata-se, nesses casos, segundo Schwarz (2000), de anáforas (ou catáforas) "complexas", representadas, em grande parte, por meio de nomes genéricos e inespecíficos (estado, fato, fenômeno, circunstância, condição, evento, cena, atividade, hipótese, etc). Estes nomes-núcleo exigem, portanto, não apenas a capacidade de interpretação da expressão em si (o rótulo), mas também a delimitação e compreensão da informação co-textual precedente ou subseqüente por eles encapsulada, ou seja, conforme Müsseler \& Rickheit (1990), o acionamento da estratégia cognitiva de formação de complexos e de interpretação de informação adicional. Ao empregar um rótulo, o produtor do texto necessita ter bem clara na mente a extensão maior ou menor de texto que 
pretende encapsular e a orientação discursiva que, com o uso do rótulo, pretende imprimir ao discurso. O leitor/ouvinte, por sua vez, ao se deparar com o rótulo, deve ser capaz de reconstruir mentalmente a porção de texto por ele encapsulada, bem como perceber a razão do uso desse e não de outro rótulo no encaminhamento do sentido por parte do produtor. É isto, aliás, que diferencia a rotulação das simples nominalizações por meio de nomes deverbais.

Assim sendo, essas expressões nominais, que são, freqüentemente (mas não apenas), introduzidas por um demonstrativo (cf. APOTHÉLOZ; CHANÊT, 1997; ZAMPONI, 2003; CAVALCANTE, 2001), desempenham funções textuais de grande relevância: não só rotulam uma parte do co-texto que as precede ou segue ( $x$ é um acontecimento, um fato, uma hipótese, uma cena etc), mas, ao fazê-lo, criam um novo referente textual que, por sua vez, passará a constituir o tema dos enunciados subseqüentes. Como formas de remissão a algo apresentado no texto ou sugerido pelo co-texto, elas possibilitam a sua ativação na memória do interlocutor, ou seja, a alocação de um novo objeto-de-discurso na memória operacional deste. Por outro lado, na medida em que operam uma refocalização da informação co-textual, elas têm, ao mesmo tempo, função predicativa, isto é, ao criarem um novo objeto-de-discurso, esses rótulos não só propiciam a progressão textual, como, em parte, são responsáveis por ela. Tratase, assim, de formas híbridas, simultaneamente referenciadoras e predicativas, isto é, veiculadoras tanto de informação dada ou inferível, como de informação nova. A essa dupla função, Schwarz (2000) vem denominando tematização remática.

\section{Classificação dos rótulos}

Inicialmente, poder-se-ia, de forma bastante provisória, dividir os rótulos em dois grandes grupos: os que nomeiam/categorizam o 'conteúdo' de proposições anteriores ou subseqüentes, e os que atuam de forma metadiscursiva com relação ao que foi ou será dito. Teríamos, pois, rótulos que recaem sobre o dictum e rótulos que recaem sobre o modus de enunciados ou segmentos textuais de extensão variada.

Em outras palavras, os rótulos relativos ao conteúdo encapsulam, de forma aparentemente 'neutra', conteúdos expressos em porções de texto precedentes ou subseqüentes, como se pode verificar em (1) e (2): 
(1) ... e eu fui à:: à Europa e a Paris numa época de muito frio eu fui... precisamente nesta época eu eu eu embarquei em novembro e voltei nas vésperas de Natal... então eu andava muito a pé... circunstância que talvez não ocorresse se eu tivesse ido no verão...(NURC/SP DID 137, p. 168-172)

(2) "O tratamento do diabetes passa por uma grande transformação. Da alçada da endocrinologia, a doença será de agora em diante considerada também uma especialidade da cardiologia. Essa ampliaçãoé decorrente da estreita relação entre o diabetes e os distúrbios cardiovasculares." (Veja, 16/06/04)

Os rótulos metadiscursivos ou metaenunciativos, por sua vez, recaem sobre o modo do dito, isto é, atribuem uma qualificação ao ato de enunciação realizado pelos personagens a que se refere o texto encapsulado, de várias formas distintas:

1. categorizando-o como um ato ilocucionário, por meio de 'nomes ilocutórios' (cf. FRANCIS, 1994), como promessa, ordem, advertência, asserção, conselho, etc.:

(3) "A pior coisa que aconteceu aos judeus foi a colônia judia dos Estados Unidos ter descoberto o holocausto." A afirmação é de um judeu norte-americano, Norman Finkelstein - autor do livro A Indústria do Holocausto (...) cujos pais estiveram em campos de concentração nazistas e que, ao contrário do resto da família, conseguiram sobreviver. (Emir Sader, O Lobby do holocausto, Caros Amigos, setembro de 2000, p. 21)

(4) “O Ministério da Saúde informa: o cigarro causa impotência". Essa advertência vem acrescentar mais um dano aos que vinham sendo anteriormente anunciados.

(5) O presidente afirmou em recente entrevista que não é um neoliberal, mas que defende um Estado Moderno (...). A explicação não convenceu os presentes.

2. categorizando-o como resultado de determinado tipo de operação cognitivodiscursiva: reflexão, ponderação, argumentação, constatação, crítica, esclarecimento, comentário, etc.): 
(6) Pinochet feriu os direitos do homem e, portanto, deve uma explicação ao conjunto da humanidade. Isso seria verdade mesmo se a maioria da população chilena o apoiasse (Hitler foi eleito em 1933, por uma grande maioria de votantes alemães. O contrário seria dizer, por exemplo, que os governos da Turquia, da Síria e do Iraque têm o direito de reprimir e assassinar os curdos, apenas porque representam, supostamente, os interesses majoritários de seus povos contra um grupo minoritário. Essa argumentação é tão ridícula quanto insustentável.(...) (José Arbex Jr., O general escapou. E agora?, Caros Amigos, ano III, no. 36, março de 2000, p.18)

3. aplicando-lhe uma denominação metalingüística (frase, sentença, termo, palavra, discurso, etc.), como em (7) e (8):

(7) Ônibus parado, as câmaras mostram. O sequiestrador desvairado, revólver na mão, mulheres sob tortura, gritos na janela, letras de batom transmitindo ameaças.

O seqüestrador, capeta incansável, no corredor do ônibus. "Vi-sivel-mente drogado", afirma um repórter de televisão."Vi-si-velmente drogado", afirma outro repórter de televisão. E no rádio se repete a frase inteira. (Ricardo Vespucci, Droga, Caros Amigos, ano IV, no. 40, julho de 2000, p.21)

(8) (...) "O programa mata a fome, mas não ajuda a diminuir a pobreza nem estimula a economia das regiões mais carentes", diz Terra, a propósito do corte das cestas básicas para as famílias mais pobres. Tem-se, nessa única sentença, os dois lados essenciais do governo FHC. Primeiro, o academicismo. Segundo, o economicismo. (Clóvis Rossi, O retrato de um governo (FSP, 28/11/00).

4. revelando uma atitude metaenunciativa do produtor com relação a uma denominação anterior presente no texto, como de distanciamento, postura crítica, ironia, etc. Poder-se-ia dizer que se trata de rótulos parafrásticos ou 'de segunda mão' (cf. CARVALHO, 2005). Anáforas desse tipo constituem, normalmente, fatos de polifonia, em que o segmento objeto de menção é atribuído à voz de outro(s) enunciador(es), da qual o locutor geralmente discorda ou, pelo menos, em relação ao qual deseja mostrar distanciamento. 
Daí, a predominância, nesses casos, do uso das aspas. Vejam-se os dois exemplos seguintes:

(9) Brasília - Uma das melhores frases da crise Waldomiro partiu do líder do PFL no Senado, José Agripino Maia (RN): “Com ou sem CPI, a oposição está bem alimentada para uma longa travessia". Não fica claro se ele inclui nessa "travessia" algo essencial: as eleições municipais de outubro, aquelas em que o PT sonha, ou sonhava, multiplicar prefeitos do próprio partido ou de aliados pelo país afora.(Eliane Castanhede, Carne aos leões, FSP, 4/3/04)

(10) Acrescente-se, como cereja sobre o bolo, uma pesquisa da Universidade de Miami, realizada com 537 integrantes do que foi descrito como "elite latina" e divulgada por todos os meios.

Nela, Lula surgiu como líder pan-americano com a melhor avaliação entre os "latinos" ricos (...) (Nelson de Sá, Do crescimento à ética, http://www1.folha.uol.com.br/fsp/brasil/fc2910200314.htm.)

\section{Funcionamento textual-discursivo dos rótulos}

Os rótulos, como facilmente se pode verificar, são multifuncionais, em virtude de atuarem no texto como instruções de relevância para a construção de sentidos. Entre as várias funções por eles desempenhadas, gostaríamos aqui de destacar as seguintes:

1. funções cognitivo-discursivas:

- formação de complexos, sua delimitação e interpretação;

- sumarização/encapsulamento e posterior categorização de um segmento textual, o que permite ao leitor/ouvinte a alocacão, na memória, de um novo referente textual, que fica disponível para servir de base a novas predicações;

- função de organização textual: ao encadearem segmentos textuais, os rótulos exercem papel de relevância na organização micro- e macroestrutural do texto. Além de constituírem importantes recursos anafóricos ou catafóricos, responsáveis pela coesão textual, são frequientemente responsáveis pelo encadeamento tópico, bem como determinantes, muitas vezes, da própria paragrafação (cognitiva e/ 
ou gráfica) do texto, visto que podem assinalar quer desvios e retomadas de tópico, quer o início de novas etapas na argumentação, como se pode observar no exemplo (11):

(11) “(...) A gravidade na superfície do astro em contração vai mais e mais aumentando e, a partir de um certo ponto, até mesmo a luz não consegue mais escapar-lhe. Forma-se, então, um buraco negro.

"Esse nome tem sua origem na interpretação oriunda da Teoria da Relatividade sobre a interação gravitacional. Dentro dessa teoria, a gravidade nada mais é que o resultado da curvatura do espaço ao redor de um corpo com massa.

"Nesse fenômeno, o espaço curva-se tanto que acabou fechandose sobre si mesmo. (...) (Romildo Póvoa Faria, "Buracos Negros", A Tribuna de Campinas, 17/5/1998, adaptado)

2. função de orientação argumentativa: os rótulos (isolados ou acompanhados de modificadores adjetivais) são meios privilegiados de condução e explicitação de pontos de vista do produtor não só no que diz respeito aos conteúdos veiculados, como também aos seus enunciadores, inscrevendo, desta forma, a argumentatividade no texto.

(12) "Na conversa que teria sido gravada em 19 de agosto, Miranda diz que o chefe ironizou a proposta, dizendo que só aceitaria como suborno "a metade de um terço do que fora anteriormente acordado", que os empresários caça-níqueis de Minas calculam em R \$ 6 milhões.

"O escândalo ocorreu uma semana depois da mais recente ação ostensiva de apreensão de máquinas em Belo Horizonte (...)" (Istoé, 06/09/2000)

(13) (...) Se a direita defendia seus interesses, a esquerda, como sempre, mergulhava em discussões intermináveis, ótimas para "seminários", sobre a chamada "via" que os partidos socialistas europeus estavam trilhando: segunda, terceira, quarta, quinta? Blairé um traidor? Jospin é um burguesinho? Esses debates intelectualóides impediram que se enxergasse outro fato histórico, certamente o nascedouro do Consenso de Berlim, ou o começo do fim do neoliberalismo. (Aloysio Biondi, Fim do neoliberalismo, a virada, Caros Amigos, julho de 2000, p.12) 


\section{Escala de argumentatividade}

É preciso frisar que, evidentemente, todos os rótulos contêm algum grau de subjetividade, pois, no momento em que o produtor, ao rotular segmentos textuais, cria um novo objeto de discurso, ele procede a uma avaliação do que é dito nesses segmentos e escolhe aquele rótulo que considera adequado para a realização de seu projeto de dizer. Mesmo no caso dos rótulos ‘de conteúdo', há sempre uma escolha e esta será necessariamente significativa em maior ou menor grau. Daí a precariedade da distinção entre os dois grupos, já que em ambos a metaenunciação se faz presente.

Por exemplo, o fato de o produtor rotular o conteúdo que está sumarizando como fato, episódio, acontecimento, evento, cena constitui sempre uma opção que, embora possa parecer 'neutra', não deixa de ser significativa. Mesmo em se tratando de rótulos de conteúdo, pode-se observar, em muitos casos, a diferença de força argumentativa resultante do uso de determinado rótulo e não de outro, como fica patente nos exemplos:

(14) Acredita-se que o ser humano poderá um dia controlar seus instintos, sentimentos e ambições, de modo a tornar a Terra um planeta de paz e fraternidade. A hipótese merece credibilidade e vale a pena pagar para ver.

(14') Acredita-se que o ser humano poderá um dia controlar seus instintos, sentimentos e ambições, de modo a tornar a Terra um planta de paze fraternidade. Esse delírio só poderia ser fruto de mentes pouco realistas.

Mas é evidente, também, que o grau de argumentatividade vai variar de um tipo de rótulo para outro. É possível, portanto, falar numa escala de argumentatividade, ao longo da qual os rótulos podem ser situados, desde aqueles aparentemente neutros, ou seja, em que o produtor opta por apresentar seu discurso como neutro, "afivelando a máscara da neutralidade" (VOGT, 1980), até aqueles dotados de elevada carga argumentativa.

Caberia aqui lembrar, ainda, a par de tudo o que ficou registrado, que os rótulos podem constituir marcas de autoria e estilo (individual ou de gênero). Ao examinar um corpus bastante extenso de matéria opinativas da revista "Caros Amigos", Carvalho (2004) verificou que há significativa diferença no uso dos rótulos pelos vários articulistas. Há os que preferem os prospectivos, outros que 
se limitam ao uso dos retrospectivos; enquanto em alguns textos, os rótulos são bastante freqüentes, em outros eles são (quase) inexistentes. Tratar-se-ia, aqui, de estilo individual, revelando preferências do produtor do texto.

Por outro lado, se procedermos a uma comparação entre gêneros diversos, veremos que a presença dos rótulos - e do tipo de rótulo - varia consideravelmente: por exemplo, devido ao seu custo de processamento, eles são muito mais freqüentes em exemplares de escrita mais elaborada, como textos de opinião, comentários, textos acadêmicos, etc. Já em textos orais informais, a presença é bem menor, prevalecendo aqueles que denominamos anteriormente rótulos 'de conteúdo': fato, coisa, caso, circunstância e alguns outros do mesmo tipo, a par de alguns de caráter metalingüístico, comofrase, sentença, por exemplo.

Nãoé demais reiterar aqui que, em todos os tipos de rótulos metadiscursivos mencionados, não se sumariza apenas o conteúdo de um segmento textual, mas focaliza-se a própria atividade enunciativa, ao qualificar esse segmento como determinado tipo de ação ou atividade discursiva; ou seja, como afirma Jubran (2003, p.97),

os referentes rotulados metalingüística ou metadiscursivamente (...) são claramente entidades discursivas, no sentido de que focalizam a atividade enunciativa, a mise-en-scène do discurso". E ainda: "em todas as ocorrências de rotulação metalingüística ou metadiscursiva, há esse jogo multiplano em que referentes textuais constitutivos do elemento-fonte anaforizado desempenham uma função informacional no texto, mas passam, no anaforizador, a se constituir como objetos de menção e qualificação no contexto da atividade enunciativa (...). (p. 98). Não há, no caso, portanto, retomada referencial, nem correferencialidade, já que se opera um desdobramento: é o próprio discurso que é tomado como seu objeto.

Cabe, também, reiterar que a operação cognitivo-discursiva de escolha das expressões metalingüísticas e metadiscursivas, entre as várias opções possíveis, é importante indício da opinião do locutor não só a respeito do discurso que está sendo rotulado, como também a respeito do próprio enunciador desse discurso (cf. van DIJK, 1988a; b; MARCUSCHI, 1991).

Marcuschi (1991), por exemplo, ao estudar os verbos introdutores de opinião, mostrou a importância da seleção desse tipo de verbos na construção 
da proposta de sentido pelo produtor do texto. Ao apresentar sua proposta, escreve o autor:

Mais do que mostrar que a neutralidade é impossível, tentarei analisar como a parcialidade se dá na introdução do discurso alheio, seja como interpretação, seleção ou avaliação. Quanto à seleção, não se trata da escolha de tópicos a reproduzir, mas da seleção dos verbos usados. Como pressuposto de trabalho, parto da premissa de que apresentar ou citar o pensamento de alguém implica, além de uma oferta de informações, também uma certa tomada de posição diante do exposto. Assim, a avaliação lingüística terá um caráter não meramente estilístico, mas sobretudo interpretativo e avaliativo. O mais notável é que isso se processa através do instrumento lingüístico usado e não mediante uma interpretação explicita paralela. Não me refiro, portanto, aos comentários; refirome tão somente às palavras que introduzem opiniões alheias com pretensão de felicidade ao pensamento do autor.

Isto também se aplica, evidentemente, aos nomes selecionados para qualificar metadiscursivamente uma ação ou atividade de linguagem, ou um processo cognitivo-discursivo que se atribui a uma pessoa mencionada no texto, bem como para ironizar, contestar, distanciar-se de algo que foi dito.

Por seu turno, van Dijk, em diversos de seus trabalhos sobre o discurso jornalístico (cf., por exemplo, 1988a; b), tem mostrado diferenças ideológicas na seleção de termos desse tipo, conforme a pessoa ou grupo a quem se atribui uma fala ou cuja fala se transcreve. Enquanto membros de uma elite (política, cultural, econômica ou outra qualquer.) asseveram, expõem, argumentam, refletem, ponderam, constatam, determinam, evidenciam e assim por diante, os membros de minorias apenas falam, dizem, depõem, negam, mentem. Dessa forma, quando se rotula e qualifica a fala dos primeiros, atribuem-se-lhes asserções, constatações, exposições, reflexões, explicações, ponderações, confirmações comentários; ao passo que os enunciados dos segundos são qualificados simplesmente como afirmações, negativas, falas, respostas ou, no máximo, como declarações, confissões ou recusas. 


\section{À guisa de conclusão}

Em razão da multifuncionalidade dos rótulos, das operações cognitivodiscursivas que põem em ação e do relevante papel que desempenham na construção textual do sentido - podendo, desta forma, constituir importante recurso para o ensino de leitura e produção de textos em sala de aula -, a pesquisa sobre o fenômeno da rotulação e, em especial, de sua face cognitiva, merece, com certeza, não só aprofundamentos teóricos, como também propostas de operacionalização didática.

\section{Referências Bibliográficas}

APOTHÉLOZ, Denis; Catherine CHANET. Défini et démonstratif dans Les nominalisations. In: DE MULDER, Walter; Carl Vetters (Ed.). Relations anaphoriques et (in)cohérence. Amsterdam: Rodopi, 1997. p.159-186.

CARVALHO, Maria Angélica F. O funcionamento textual-discursivo dos rótulos em artigos de opinião. 2005. Tese (Doutorado) - IEL/UNICAMP, 2005.

CAVALCANTE, Mônica M. Demonstrativos - uma condição de saliência. II Congresso Internacional da ABRALIN, Fortaleza, 2001.

CONTE, Elisabeth. Anaphoric encapsulation. Belgian Journal of Linguistics: Coherence and anaphora, v. 10, p.1-10, 1996.

FRANCIS, Gill. Labelling discourse: an aspect of nominal-group lexical cohesion. In: COULTHARD, Malcolm (Ed.). Advances in written text analysis. Londres: Routledge, 1994.

JUBRAN, Clélia C. S. O discurso como objeto-de-discurso em expressões Nominais anafóricas. Cadernos de Estudos Lingüísticos, Campinas, IEL/Unicamp, 44, p.93-104, 2003.

KOCH, Ingedore G. Villaça. Expressões referenciais definidas e sua função textual. In: DUARTE, Lélia Parreira (Org.). Para sempre em mim: homenagem a Ângela Vaz Leão. Belo Horizonte: CESPUC, 1999. p. 138-150.

KOCH, Ingedore G. Villaça. Desvendando os segredos do texto. São Paulo: Cortez, 2002.

MARCUSCHI, Luiz Antônio. A ação dos verbos introdutores de opinião. INTERCOM - Revista Brasileira de Comunicação, São Paulo, ano XIV, n. 64, p. 74-92, 1991. 
MÜSSELER, J.; RICKHEIT, G. The Cognitive Resolution of Anaphoric Noun References. Journal of Semantics, v. 7, n. 3, p. 221-244, 1990.

SCHWARZ, Monika. Indirekte Anaphern in Texten. Tübingen: Niemeyer, 2000. VAN DIJK, Teun A. News as discourse. Hillsdale, N. J.: Erlbaum, 1988a.

VAN DIJK, Teun A. News Analysis. Case studies of international and national news in the press. Hillsdale, N.J.: Erlbaum, 1988b.

VOGT, Carlos A. Linguagem, pragmática e ideologia. São Paulo: Hucitec, 1980.

ZAMPONI, Graziela. Processos de referenciação: anáforas indiretas e nominalizações. 2003. Tese (Doutorado) - IEL/Unicamp, 2003. 